\title{
TOTAL ROMAN REINFORCEMENT IN GRAPHS
}

\author{
H. Abdollahzadeh Ahangar ${ }^{1}$, J. Amjadi ${ }^{2}$ \\ M. Chellali ${ }^{3}$, S. NAZARi-Moghaddam ${ }^{2}$ \\ AND \\ S.M. SHEIKHOLESLAMI ${ }^{2}$ \\ ${ }^{1}$ Department of Mathematics \\ Babol Noshirvani University of Technology \\ Babol, I.R. Iran \\ ${ }^{2}$ Department of Mathematics \\ Azarbaijan Shahid Madani University \\ Tabriz, I.R. Iran \\ ${ }^{3}$ LAMDA-RO Laboratory, Department of Mathematics \\ University of Blida \\ B.P. 270, Blida, Algeria \\ e-mail: ha.ahangar@nit.ac.ir \\ \{j-amjadi;s.nazari;s.m.sheikholeslami\}@azaruniv.ac.ir \\ m_chellali@yahoo.com
}

\begin{abstract}
A total Roman dominating function on a graph $G$ is a labeling $f$ : $V(G) \rightarrow\{0,1,2\}$ such that every vertex with label 0 has a neighbor with label 2 and the subgraph of $G$ induced by the set of all vertices of positive weight has no isolated vertex. The minimum weight of a total Roman dominating function on a graph $G$ is called the total Roman domination number of $G$. The total Roman reinforcement number $r_{t R}(G)$ of a graph $G$ is the minimum number of edges that must be added to $G$ in order to decrease the total Roman domination number. In this paper, we investigate the properties of total Roman reinforcement number in graphs, and we present some sharp bounds for $r_{t R}(G)$. Moreover, we show that the decision problem for total Roman reinforcement is NP-hard for bipartite graphs.
\end{abstract}

Keywords: total Roman domination number, total Roman reinforcement number.

2010 Mathematics Subject Classification: 05C69. 


\section{REFERENCES}

[1] H. Abdollahzadeh Ahangar, J. Amjadi, S.M. Sheikholeslami and M. Soroudi, On the total Roman domination number of graphs, Ars Combin., to appear.

[2] H. Abdollahzadeh Ahangar, M.A. Henning, V. Samodivkin and I.G. Yero, Total Roman domination in graphs, Appl. Anal. Discrete Math. 10 (2016) 501-517. doi:10.2298/AADM160802017A

[3] J. Amjadi, S. Nazari-Moghaddam and S.M. Sheikholeslami, Global total Roman domination in graphs, Discrete Math. Algorithms Appl. 9 (2017) ID: 1750050. doi:10.1142/S1793830917500501

[4] J. Amjadi, S.M. Sheikholeslami and M. Soroudi, Nordhaus-Gaddum bounds for total Roman domination, J. Comb. Optim. 35 (2018) 126-133. doi:10.1007/s10878-017-0158-5

[5] J. Amjadi, S. Nazari-Moghaddam and S.M. Sheikholeslami and L. Volkmann, Total Roman domination number of trees, Australas. J. Combin. 69 (2017) 271-285.

[6] E.J. Cockayne, R.M. Dawes and S.T. Hedetniemi, Total domination in graphs, Networks 10 (1980) 211-219.

doi:10.1002/net.3230100304

[7] E.J. Cockayne, P.A. Dreyer Jr., S.M. Hedetniemi and S.T. Hedetniemi, Roman domination in graphs, Discrete Math. 278 (2004) 11-22. doi:10.1016/j.disc.2003.06.004

[8] O. Favaron, H. Karami, R. Khoeilar, and S.M. Sheikholeslami, On the Roman domination number of a graph, Discrete Math. 309 (2009) 3447-3451. doi:10.1016/j.disc.2008.09.043

[9] M.R. Garey and D.S. Johnson, Computers and Intractability: A Guide to the Theory of NP-Completeness, (Freeman, San Francisco, 1979).

[10] M.A. Henning, A survey on selected recent results on total domination in graphs, Discrete Math. 309 (2009) 32-63. doi:10.1016/j.disc.2007.12.044

[11] M.A. Henning, N. Jafari Rad and J. Raczek, A note on total reinforcement in graphs, Discrete Appl. Math. 159 (2011), 1443-1446. doi:10.1016/j.dam.2011.04.024

[12] M.A. Henning and A. Yeo, Total Domination in Graphs (Springer, New York, 2013). doi:10.1007/978-1-4614-6525-6

[13] N. Jafari Rad and S. Sheikholeslami, Roman reinforcement in graphs, Bull. Inst. Combin. Appl. 61 (2011) 81-90.

[14] C.-H. Liu and G.J. Chang, Roman domination on 2-connected graphs, SIAM J. Discrete Math. 26 (2012) 193-205. doi:10.1137/080733085 
[15] C.-H. Liu and G.J. Chang, Upper bounds on Roman domination numbers of graphs, Discrete Math. 312 (2012) 1386-1391.

doi:10.1016/j.disc.2011.12.021

[16] C.-H. Liu and G.J. Chang, Roman domination on strongly chordal graphs, J. Comb. Optim. 26 (2013) 608-619.

doi:10.1007/s10878-012-9482-y

[17] P. Pavlič and J. Žerovnik, Roman domination number of the Cartesian products of paths and cycles, Electron. J. Combin. 19 (3) (2012) \#P19.

[18] C.S. Revelle and K.E. Rosing, Defendens Imperium Romanum: a classical problem in military strategy, Amer. Math. Monthly 107 (2000) 585-594. doi:10.1080/00029890.2000.12005243

[19] N. Sridharan, M.D. Elias and V.S.A. Subramanian, Total reinforcement number of a graph, AKCE Int. J. Graphs Comb. 4 (2007) 197-202.

[20] I. Stewart, Defend the Roman Empire, Sci. Amer. 281 (1999) 136-139. doi:10.1038/scientificamerican1299-136

[21] I.G. Yero and J.A. Rodríguez-Velázquez, Roman domination in Cartesian product graphs and strong product graphs, Appl. Anal. Discrete Math. 7 (2013) 262-274. doi:10.2298/AADM130813017G

Received 19 June 2017

Revised 21 November 2017

Accepted 21 November 2017 